\title{
Restoring wetland plant diversity: a comparison of existing and adaptive approaches
}

\author{
Joy B. Zedler \\ Botany Department and Arboretum, University of Wisconsin, 430 Lincoln Drive, Madison, WI 53706, USA \\ (e-mail: jbzedler@wisc.edu; phone: +608-262-8629; fax: +608-262-7509)
}

Received 9 January 2003; accepted in revised form 6 May 2003

Key words: Halophytes, Marshes, Monotypes, Transplant mortality, Vegetation, Wetland restoration

\begin{abstract}
Most restoration projects are not designed or assessed in ways that identify cause-effect relationships. When plants die, even detailed postmortem examinations cannot pinpoint causes; e.g., mortalities of 7\% vs. 90\% in two salt marsh transplantation projects were attributable to differences in hypersalinity and sedimentation, but other effects could not be ruled out. Adaptive restoration (the experimental testing of alternative approaches in restoration sites), however, can clarify cause-effect relationships, while simultaneously restoring plant diversity and informing future restoration efforts. Projects in Tijuana Estuary (California) and Greene Prairie (Wisconsin) demonstrate the approach: (1) A large field experiment at Tijuana Estuary showed that species-rich plantings of halophytes accelerated the development of ecosystem structure and function (over single-species plantings) while simultaneously vegetating an intertidal plain. The six-species assemblages produced more complex canopies and accumulated more biomass and nitrogen than singlespecies and unplanted plots. (2) Also at Tijuana Estuary, an experiment is testing the ability of tidal creek networks to accelerate revegetation and increase food-web support (via increased growth of plants, invertebrates, and fish) in an 8-ha project that simultaneously restored tidal flushing. (3) In Greene Prairie, the ability to establish 33 native species is being tested as replacements for an invasive grass (Phalaris arundinacea). In each case, the adaptive approach informs both the science and practice of restoration. Without experimentation, restorationists are hard-pressed to explain past mortality and to suggest better methods for restoring structure and function. Adaptive restoration can provide the knowledge required, especially when large projects are implemented as sequential modules with experiments that sequentially provide essential information.
\end{abstract}

\section{Introduction}

A comparison of efforts to revegetate restoration sites in California (CA) and Wisconsin (WI) is useful for identifying constraints on wetland restoration. Although physiography, climate, and disturbance regimes are quite different, wetlands in both regions are experiencing declines in plant diversity, as many native species drop out and one becomes the overwhelming dominant. In the coastal wetlands of southern CA, Salicornia virginica (Figure 1) is replacing a once-diverse salt marsh community (Zedler et al. 2001), and in southern WI, Phalaris arundinacea (Figure 2) is replacing diverse wet meadows (Maurer et al. in press). In both cases, environmental conditions are changing in ways that are not readily reversible.

Standard restoration approaches are not likely to teach us how to restore native plant diversity. A typical salt marsh restoration in CA involves 


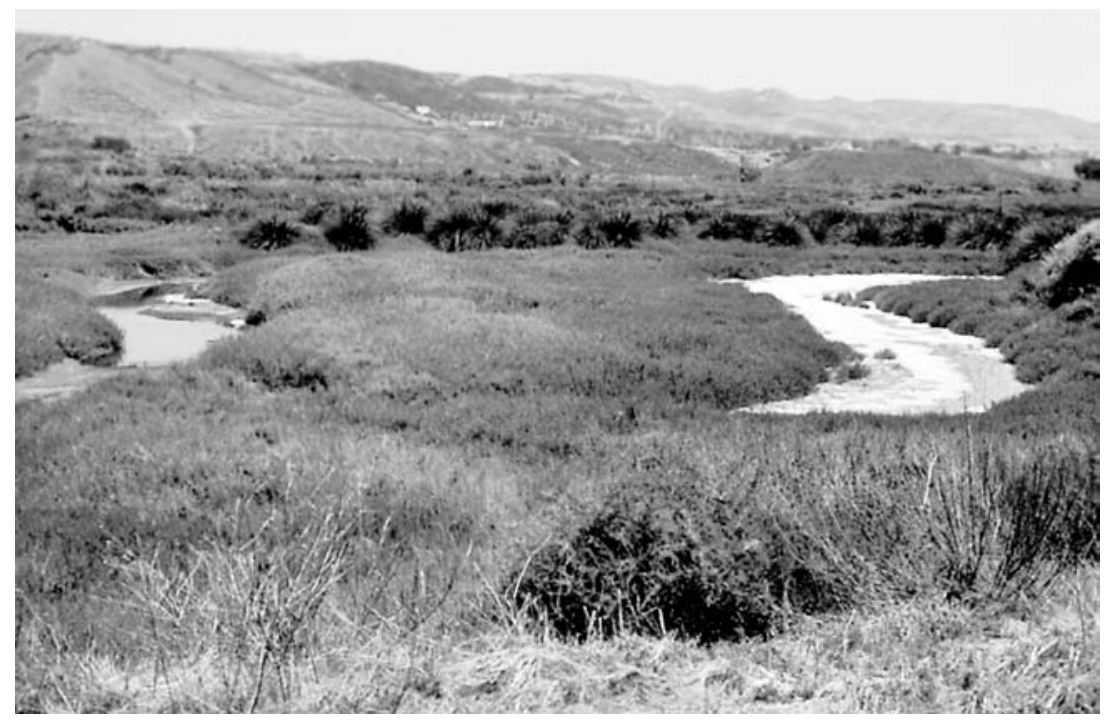

Figure 1. Monotypic pickleweed (S. virginica; center of photo) in the southern arm of Tijuana Estuary, San Diego County, California. At this site, tidal flushing has been impaired since at least 1970 (pers. observ.). Disturbed upland appears in the foreground and tussocks of spiny rush (Scirpus acutus) are visible in the background, with bluffs bordering Mexico on the horizon. White areas show salt crusts that accumulate where tidal inundation is rare.

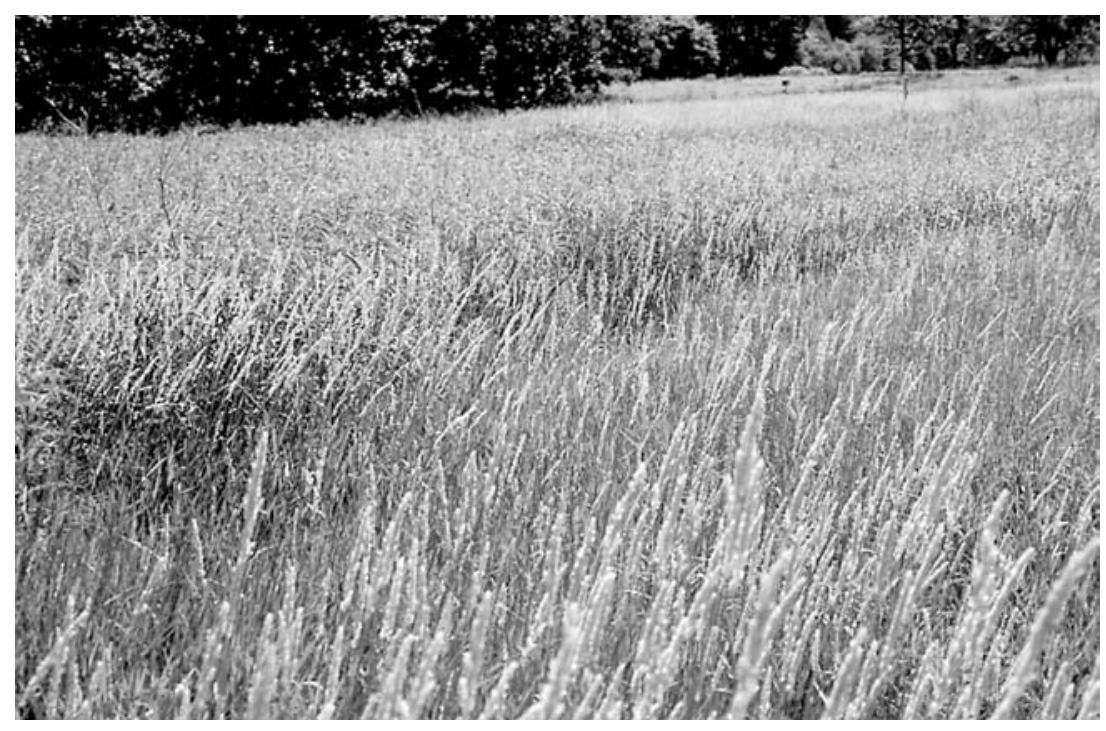

Figure 2. Monotypic reed canary grass (P. arundinacea) in one of Wisconsin's many hydrologically disturbed wetlands. Few native plant species can coexist with this tall, dense, clonal grass.

grading a smooth slope and planting one or two native species, and a typical freshwater marsh restoration in WI involves the creation of shallow depressions or the breaking of drainage tiles and plugging of drainage ditches to allow water to accumulate in existing depressions and plants to establish on their own (Kitchen 2002). If diverse vegetation develops (a low probability), observers would not know why; if the invading vegetation is weedy (most likely outcome), one would learn nothing about how to prevent dominance by invasive species or how to favor native species. If, as an alternative, the restoration project were designed as an experiment, even one as simple as providing 
areas with and without seeding of native plant species, the increased implementation effort would provide opportunities for study, e.g., evaluation of species that can establish in different microsites. This alternative approach of designing and implementing restoration sites as field experiments that can test alternative approaches (adaptive restoration; Zedler and Callaway 2003) offers opportunity to learn while restoring. Learning opportunities increase in large sites, if restoration is undertaken as a series of smaller modules and implemented in tandem, such that results from experiments in the early modules can inform later modules, gradually accumulating information on how best to restore diversity.

\section{Environmental settings}

Southern CA is mountainous and dry, with very little habitat suitable for the development of wetlands. The region has a Mediterranean-type climate, with mild temperatures year-round and very little rainfall (mean $=\sim 30 \mathrm{~cm} / \mathrm{yr}$ ). Rain falls intermittently during the cool winter months, with high variability from day-to-day and year-to-year. Catastrophic storms and flooding can occur in late fall, winter, or early spring. The mountainous topography breaks up the region into many watersheds with rivers that flow to the ocean. Some rivers flow year round; others are intermittent streams subject to occasional flooding. Where they meet the coast, small estuaries form and allow development of salt marshes, although the area of coastal wetland was never large. The continental shelf drops off so that only the largest bays, such as San Diego and Mission Bays in California, and San Quintin Bay in Baja California Norte have suitable topography for extensive wetlands. Most of the southern CA coast is urbanized, with large cities encroaching on small coastal wetlands. About $90 \%$ of the coastal wetland area has been dredged or filled. San Diego Bay and Mission Bay once had the largest areas of coastal wetland in San Diego county. Now, Tijuana Estuary is the largest remnant wetland, owing to extensive dredging of San Diego Bay for shipping and Mission Bay for recreational beaches.

The Upper Midwest is relatively flat, with large areas of former glacial lakes and outwash plains across the five-state region that includes WI,
Minnesota (MN), Iowa (IA), Missouri (MO), and Illinois (IL). The climate is temperate, and annual precipitation is about $50-100 \mathrm{~cm}$. The combination of flat topography and moderate precipitation allows extensive wetland formation. Historically, $15 \%$ of the five-state Upper Midwest was wetland, with a range of $11 \%$ in IA to $28 \%$ in MN (Dahl 1990). Drainage of the hydric soils throughout much of the region has reduced the area of wetlands by 61\% (Dahl 1990). Losses of wetland were greatest $(>80 \%)$ in IA, IL, and MO. Today, only $1.2 \%$ of IA is wetland while MN still has $16.2 \%$ of its surface area in wetlands. While many wetlands persist, they typically have altered hydrologic conditions, excess nutrient inflows, and aggressive invasive plants. In the worst cases, the wetlands are dominated by a single invasive plant species, namely, reed canary grass ( $P$. arundinacea). Using satellite imagery, WI Department of Natural Resources has mapped over 40,000 ha of wetlands dominated by this invasive grass (T. Bernthal, unpubl. data).

\section{Shifts towards single-species dominance}

In both southern CA and the Upper Midwest, the loss and degradation of wetlands has had serious consequences for biodiversity. Of the species known to depend on coastal wetlands in southern $\mathrm{CA}$, at least 24 species of birds, insects, herpetofauna, and plants are increasingly rare, with several endangered or threatened with extinction (Zedler et al. 1992). Altered hydrologic conditions have simplified the vegetation. The changes involve more frequent blockage of river mouths by sand, resulting in loss of tidal flows coupled with more frequent large rainfalls that bring sediments into the wetlands. In 1974, a quarter-square-meter of tidal marsh plain supported 4.5 species; today, the average is about 2.0, with $S$. virginica (pickleweed) the overwhelming dominant (Zedler et al. 2001). Pickleweed is a member of the Chenopodiaceae; it is perennial, clonal, succulent, and capable of high productivity. Furthermore, it tolerates both tidal and nontidal conditions. Its biomass increases when soils are better drained, as occurs when tidal flushing is constrained (Figure 1). It can dominate where other species are eliminated by salinity and drought stress, and it is a strong competitor (Covin and Zedler 1988). Of the many functions 


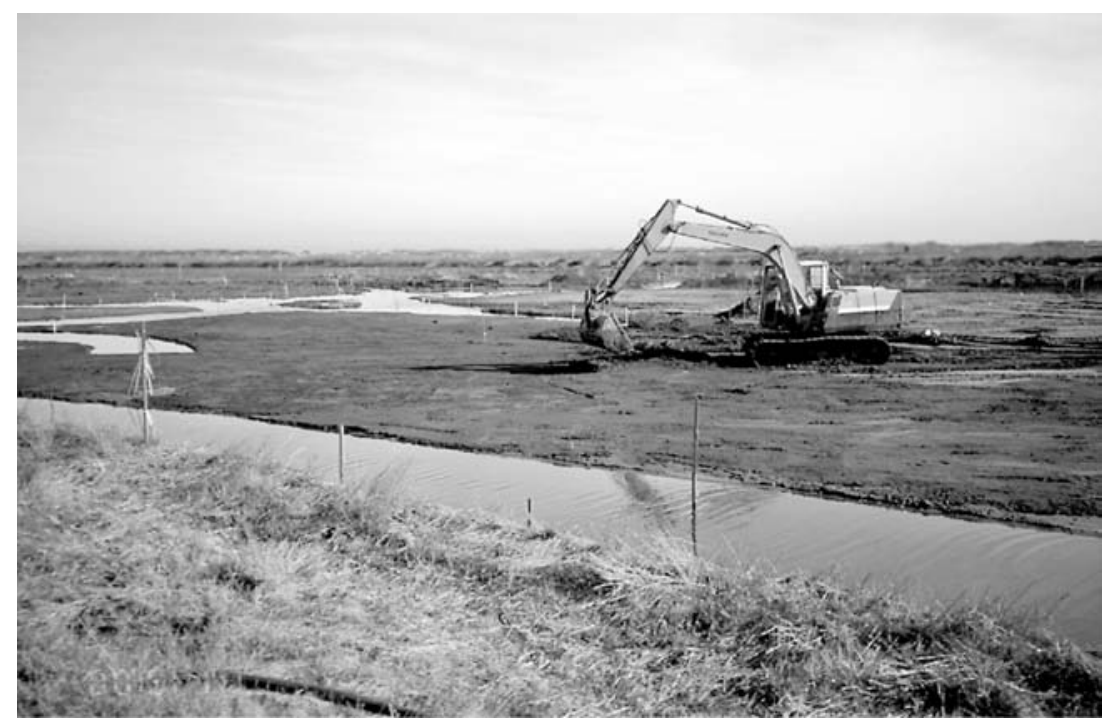

Figure 3. Excavation of sediments to restore an 8-ha marsh at Tijuana Estuary, San Diego county, CA. Excavation was designed to set up a large field experiment. On the left is one of three replicate marsh-plain areas having tidal creeks; on the right is one of three marshplain areas without tidal creeks.

performed by southern CAs coastal wetlands, biodiversity support is the most highly valued by the public (e.g., bird watchers, hikers). The effects of conversion from fully tidal to nontidal conditions are becoming clear; most native plant species are lost (Zedler et al. 2001); invertebrate foods decline; and marsh-feeding fishes lose basic resources (Madon et al. 2001).

In WI, invasive plant species have crowded out much of the native wetland vegetation. While a natural sedge meadow might support an average of 11 plant species $/ \mathrm{m}^{2}$, the most degraded sites support only one dominant (reed canary grass; Figure 2) and 2-3 rare, weedy associates (Werner and Zedler 2002). Dual impacts of surface water inflow explain this shift; the nutrients and sediments that flow into disturbed sites simultaneously make the site more invasible and the invader more aggressive (Maurer et al. in press; Kercher and Zedler 2004). The sediments create canopy gaps and simplify the topographic heterogeneity (sedge tussocks) that supports species-rich vegetation, the reed canary grass seedlings establish in gaps where light is plentiful, and the seedlings grow vertically and horizontally (via vegetative reproduction) most rapidly where nutrients are abundant.

Like pickleweed, reed canary grass is highly productive under a variety of ecological conditions. In the Upper Midwest, it grows in both uplands and wetlands and tolerates a wide range of hydroperiods (Kercher and Zedler in review). Its competitive ability results in part from low-density (air-filled) tissues that allow it to spread leaves vertically and horizontally throughout the canopy with relatively low investment in carbon (Miller and Zedler 2002). In addition, the species is flexible in its growth habitat, changing in response to both physicochemical conditions (Maurer and Zedler 2002) and competitors (Miller and Zedler 2003). The conversion of a diverse marsh to monotypic reed canary grass has unknown effects on animals and nutrient cycling (e.g., nitrogen removal), but the loss of plant diversity is obvious.

\section{Potential for restoring diverse vegetation}

Southern CA has little potential for expanding the area of coastal wetland, because so little shoreline is undeveloped. Most of the restoration activities involve "remodeling", i.e., making intermittently tidal wetlands fully tidal. This involves massive earthmoving to remove accumulated sediments from channels and increase the volume of tidal water that can flow in and out of the estuary and its salt marshes (Figure 3). However, during nontidal conditions sediments accumulate on the 


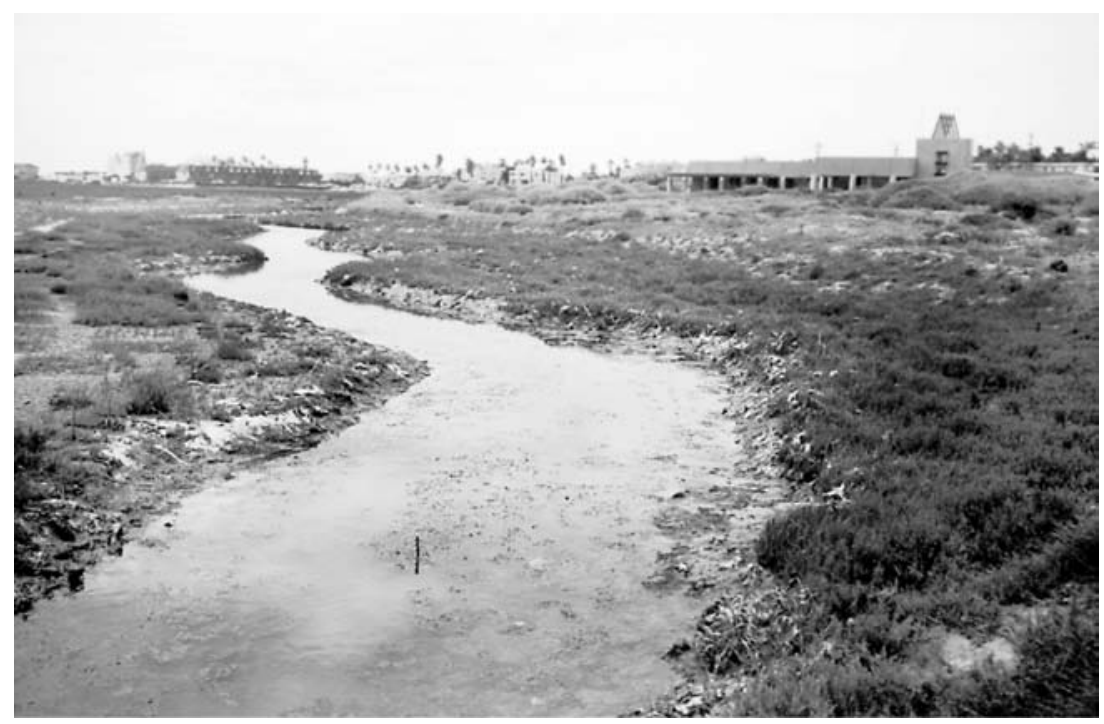

Figure 4. Tidal channel and salt marsh-plains excavated from disturbed upland at Tijuana Estuary. The marsh-plain on the right was planted with cordgrass plugs, obtained from blocks of sod (Figure 5) salvaged from a natural marsh area where the new tidal channel was connected to an existing tidal creek. The marsh-plain on the left was planted as and experiment, using $872 \times 2$-m plots. The left marsh-plain was fully vegetated within 4 years and retained all planted species. Most of the marsh-plain on the right converted to pickleweed (S. virginica).

marsh plain and raise elevations to levels that favor pickleweed over a more diverse community. Hence, excavation of channels and restoration of tidal flows does not suffice to restore plant diversity, because sediments elevate the marsh plain. Pickleweed remains dominant, because other species either do not recruit or cannot recruit given somewhat drier conditions and a dense canopy of pickleweed (Lindig-Cisneros and Zedler 2002).

In the Upper Midwest, large areas of wetlands drained for agricultural purposes can be restored by plugging drainage ditches and breaking the perforated tiles that underlie drained fields. Thousands of prairie wetlands have already been restored in MN (Galatowitsch and van der Valk 1996) and WI (Kitchen 2002) by reducing drainage or renewing water supplies, but such wetlands typically support only a few invasive species, rather than the natural levels of plant diversity (Galatowitsch and van der Valk 1996). Unless other species are planted and sites are managed to control this aggressive invader, reed canary grass is likely to become dominant (Maurer et al. in press).

In both CA and WI, wetland area needs to be restored to enhance plant diversity, but in neither region are methods available that can reliably achieve more than monotypic vegetation. Current approaches differ in their ability to teach us how to establish and sustain diverse vegetation.

\section{Alternative approaches and their ability to achieve predictability}

\section{Trial and error}

At Tijuana Estuary, a newly-excavated marsh plain (Figure 4) was planted with plugs of salvaged cordgrass (Spartina foliosa; Figure 5) in 1997 to mitigate the damages of excavating a tidal channel and to expand nesting habitat for an endangered bird. Cordgrass established and persisted for a few years, but the site is now a virtual monotype of pickleweed (pers. observ.). We can only speculate about causes of the cordgrass mortality, because environmental conditions were not assessed. The $\sim \$ 100,000$ salvage-and-transplant program was either a worthwhile project that fell victim to unrecorded stresses or a wasted effort that should not be repeated. The trial-and-error approach could not clarify cause-effect.

In Madison, WI, substantial effort went into restoring diverse sedge meadow vegetation to mitigate loss of wetland during causeway construction. 


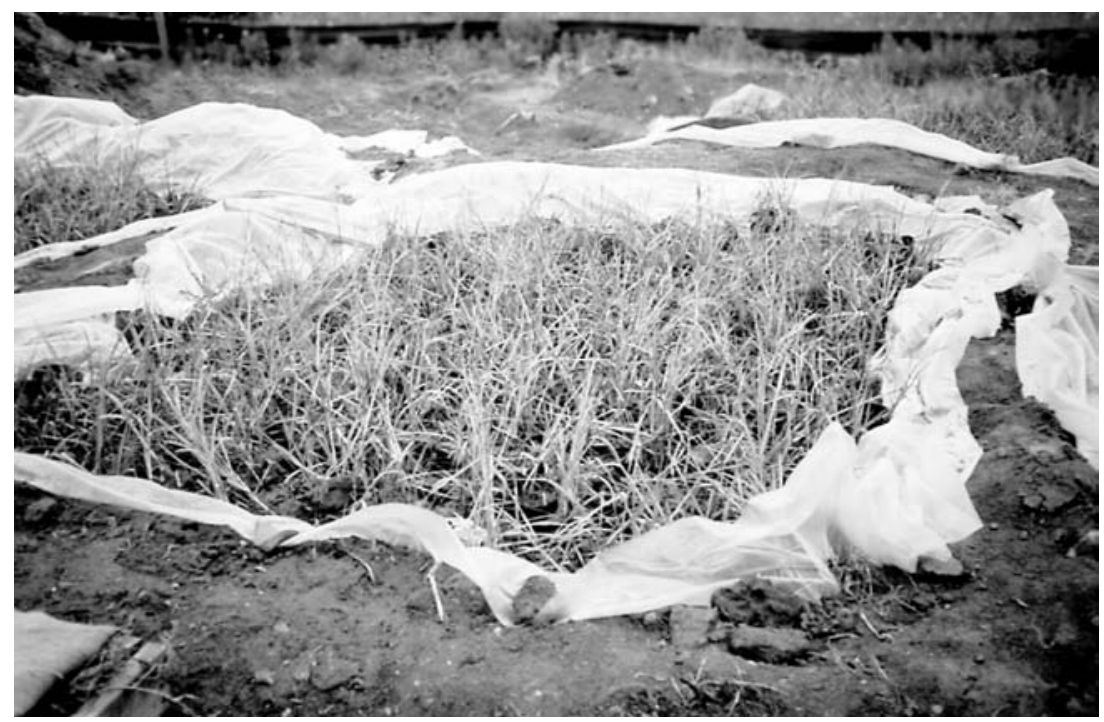

Figure 5. Cordgrass salvaged as a large block of sod during excavation of a tidal channel at Tijuana Estuary (near the site in Figure 4). Sod was removed intact, moved on pallets, held in plastic-lined and watered impoundments while the transplantation site was excavated, then cut into smaller units (plugs) that were transplanted to the new marsh plain.

A 5-year monitoring program was conducted by the Department of Transportation, and Ashworth (1997) reported over 20 species of nonweedy native plants on the site. Also, Hey and Philippi (1999) showcased the project along with three others across the country in their "case for wetland restoration". Following a major flood, the site converted to a monotype of cattails (Typha spp., Q. Carpenter, UW, pers. comm.). Cattails remain the overwhelming dominant (pers. observ.). It is tempting to conclude that flooding caused the vegetation shift, but because monitoring and research had ceased, other causes cannot be ruled out. This trial-and-error approach had limited ability to predict outcomes of future attempts to create and sustain species-rich vegetation.

\section{Postmortem examination}

More detailed examinations of transplant mortality are warranted in seeking cause-effect relationships. In southern CA (Tijuana Estuary), the US Fish and Wildlife Service, CA State Coastal Conservancy, and others excavated sediments to add tidal flushing to 0.5 ha of disturbed upland and 8 ha of former salt marsh. The smaller site became tidal in 1997 and the larger was opened to tidal flushing in February 2000. In separate research projects, we planted seedlings to the smaller site in April 1997 (Keer and Zedler 2002) and to the larger in April 2000. Of the thousands of seedlings transplanted to each site, we found $7 \%$ and $90 \%$ survival, respectively. A postmortem investigation of the differential mortality (Zedler et al. 2003) eliminated two potential causes, namely, the preparation of seedlings and weather conditions, which were similar for both experimental plantings. Data on salinity and sedimentation helped to explain the differences in survival, as both were greater at the high-mortality site. Why these variables differed by site can only be speculated, however. The history of each site (former marsh soil vs. upland subsoil), its size ( 8 vs. 0.5 ha), and location relative to the tidal channel (terminal point vs. alongside) could have combined to increase plant stress. That is, the large site with darker substrate could have become warmer when inundated by tides, concentrating salts in minor depressions where water impounded to create shallow pools. The smaller site was smoothly sloped and well drained; its lighter-colored substrate likely reflected more light, stayed cool and concentrated less salt. In addition, the channel from the mouth to the large site had accumulated fine material over decades of sluggish tidal action; that material was likely mobilized with increased tidal flow and 
transported into the newly excavated marsh, where particles dropped out on the marsh plain at slack tide. Site history, size, and location probably interacted to stress transplants by creating conditions of high salinity and heavy sedimentation, but other differences cannot be ruled out. The postmortem exercise eliminated two factors and implicated two others as causes of high mortality, but it is still not clear how best to establish and sustain species-rich vegetation.

\section{Adaptive restoration: the design of restoration sites to test hypotheses}

Today, most restoration projects are designed and implemented without incorporating experiments or research. Hence, when problems develop, causes are hard to pinpoint. Adaptive restoration is an alternative, wherein the site is designed to test alternative methods of restoration, and ecosystem development is followed over the long term. This approach can identify cause-effect relationships, while simultaneously accomplishing the goal of revegetation.

At Tijuana Estuary, catastrophic flooding has deposited sediments across $>200$ ha of former wetland. In places, sediments are over $2 \mathrm{~m}$ deep. Excavation and restoration of tidal flushing have been designed as an adaptive restoration program, with modular, phased projects that incorporate experiments. An experimental approach is necessary, because it is not immediately obvious how to enhance populations of rare and valued species, which is the overall management goal. Over time, knowledge from initial experimental modules will inform subsequent modules, and phasing is practical, because costs preclude restoring all 200 ha at once (e.g., an 8-ha effort cost \$3.1 million).

The first module was small ( 0.5 ha) and suited for testing hypotheses about establishing a diversity of plants. We tested several extensions of Egler's (1954) "initial floristic composition hypothesis", that secondary succession is strongly influenced by propagules at the site at the time of disturbance. We divided one 90 -m-long segment of marsh plain alongside the tidal channel (Figure 4) into five blocks. We then planted seedlings (90 plants/ $2 \times 20$-m plot) in assemblages of one, three, and six species (and no seedlings as a control, total of
87 plots) to test four hypotheses:

1. Halophytes have differential recruitment and establishment capability.

2. Species-rich plantings will produce more complex canopies.

3. Species-rich plantings will accumulate more biomass and $\mathrm{N}$.

4. Species-rich plantings will slow recruitment (and resist compositional shifts).

The experiment supported all four hypotheses, with the following results:

1. Only three halophytes self-recruited with any regularity (pickleweed, annual pickleweed (Salicornia bigelovii), and sea-blite (Suaeda esteroa); Lindig-Cisneros and Zedler 2002). Hence, we learned that the remaining five species must be planted to ensure their presence in restoration sites, and that two of the good recruiters (annual pickleweed and sea-blite) would need to be introduced unless a good seed source is present nearby. Without such plantings, the most likely outcome would be a monotype of pickleweed. In fact, plantings of pickleweed should be avoided (in contrast, pickleweed was the only species introduced to a mitigation site at Batiquitos Lagoon, northern San Diego County).

2. Six-species assemblages produced canopies with more layers than in plantings with three and one species, indicating that species-richness accelerates canopy development (Keer and Zedler 2002). Furthermore, because canopies were assessed in multiple ways, we learned that layering (number of hits from a rod lowered through the canopy) is a better indicator of complexity than cover estimation, which is the most common technique used in monitoring programs.

3. In the field experiment, species-rich plantings accumulated more biomass and nitrogen than single-species plantings, yielding further evidence that ecosystem development can be accelerated by manipulating plantings (Zedler et al. 2001; Callaway, unpubl. data). A complementary greenhouse experiment (G. Sullivan unpubl. data), which replicated each of the 32 assemblages, explained the results in the field by demonstrating that greater biomass was achieved by both complementarity, i.e., higher yields of species when grown in combination than alone, and species effects, i.e., chance inclusion of highly-productive species. The most productive species were those that have wide 
ecological amplitude and broad spatial distribution (Zedler et al. 2001), namely, pickleweed, alkali heath (Frankenia salina), and salt marsh daisy (Jaumea carnosa). Enhanced nitrogen accumulation was observed in the greenhouse, as well, and one species was shown to be a superior concentrator of nitrogen (Triglochin concinna), especially in its tap root. After 2 years' growth, this small-statured species was capable of reducing the biomass of various assemblages, even those with the most productive species.

4. Species-rich plantings reduced recruitment in year 3 (Lindig-Cisneros and Zedler 2002). In years 1-2, physical factors were more important to recruitment, with fewer seedlings where soil moisture was lower and elevation and salinity were higher. As seedlings recruited into plots where they were not planted, our one-, three- and sixspecies treatments began to converge in species richness, but differences in dominance remained as a legacy of initial planting conditions.

We concluded that, to accelerate functions and enhance diversity, one should plant all members of the local species pool, including plantings in a range of microsites that can favor individual species. In contrast, we were unable to draw any conclusions from the other half of the restoration site, which was not set up as an experiment.

When the second, much larger restoration site (8 ha) was being planned for Tijuana Estuary, we drew on results of the first site (i.e., which species need to be planted) and designed new experiments on plant spacing and soil amendments that would add to previous knowledge. We hypothesized that,

5. Cordgrass planted at 2-m intervals would close canopy sooner and grow taller than plantings at 4-m intervals.

6. Tightly planted clusters of five-species would develop dense canopies more rapidly than widelyspaced plantings.

7. Kelp compost (a seaweed industry byproduct), would enhance plant growth when rototilled into the soil prior to planting cordgrass plugs and marsh-plain seedlings.

In addition, we tested theory that is relevant at the large scale, namely that heterogeneity strongly affects the development of ecosystem structure and functioning. We predicted that the excavation of tidal creeks into the marsh plain would create microsites and support more speciesrich vegetation, as in a reference marsh (Zedler et al. 1999). Also, our previous work on tidal creek-marsh interactions suggested that tidal creeks would support more invertebrates and enhance feeding by fishes (Desmond et al. 2000; West and Zedler 2000; Madon et al. 2001). Hence, we proposed an experimental test of the effect of excavating tidal creeks on community structure and ecosystem functioning. Three hypotheses were developed:

8. Tidal creek networks will accelerate revegetation rates and support more plant species.

9. Tidal creek networks increase food-web support, leading to greater fish growth.

10. Where plant growth is maximum, algal growth will be reduced (by shading) and invertebrate foods will be reduced (by decreased plant food).

The 8-ha site has three replicate areas with a tidal creek network and three without, and tests of hypotheses 5-10 are underway. While detailed results are not yet available, the variation in responses of individual replicates (at the 1-ha scale) already shows that prediction from any single replicate would be unwise. Only the differences that recur across replicate areas with tidal creeks (and shown to differ from smooth marsh plains) will be attributable to increased topographic heterogeneity.

The versatility of adaptive restoration is illustrated by an example from WI, where local wet meadows become dominated by reed canary grass (P. arundinacea) following hydrological modifications (inflows of sediment and nutrient-rich stormwater; Maurer et al. in press; Werner and Zedler 2002; Kercher unpubl. data). The inflows typically cannot be stopped, so restoration per se is rarely possible. However, reed canary grass can be inhibited with herbicides, and an alternative assemblage of native wetland species might be able to replace the invasive if planted early and if composed of the most competitive species (e.g., tall, broad-leaved forbs that absorb light well and produce clones that dominate root space, combined with compatible associates that form a dense matrix above and below ground). Such assemblages might be naturally occurring or novel mixtures that only occur in sites with novel conditions (such as those receiving stormwater runoff). 
The response of 12 native wet prairie species to individual and combined effects of altered hydroperiods, sediment inflows, and nutrient enrichment were first tested in a mesocosm experiment $(3 \times 3 \times$ 3 -factor design, 5-fold replication, 12 native species). Native species dropped out of the system in sequences that help us prescribe plantings for restoration sites (Kercher and Zedler in review). We then scaled up efforts to a 3-ha restoration site that is dominated by reed canary grass (Lower Greene Prairie, UW-Madison Arboretum). In August 2001 and again in August 2002, we used glyphosate herbicide to kill reed canary grass in replicate experimental plots (4@25 ×60 m).We burned plots in spring and again in late fall 2002. In December 2002, Julia Wilcox planted 33 native species (from seed) in the four treatment plots, leaving four control plots with the intact monotypic vegetation. A second (spring 2003) planting of seeds is pending suitable weather conditions. We hypothesize that native species will establish differentially according to topographic position (as predicted from the mesocosm experiment and from natural distributions); we further expect differential responses to competition from reed canary grass, which will reinvade over the long term. Future restoration projects will benefit from knowledge of the native species than can best establish in a variety of microsites, as well as data on long-term persistence of those that withstand reinvasion by reed canary grass.

\section{Summary}

Trial-and-error approaches to restoration yield little predictability. Examples are the inability to predict when species-rich sedge meadows in Madison, WI, will convert to cattails and when cordgrass plantings will convert to pickleweed in Tijuana Estuary, CA.

The postmortem examination of different outcomes is useful in eliminating some causes, e.g., two salt marsh restoration sites with $7 \%$ vs. $90 \%$ mortality differed in hypersalinity and sedimentation (likely proximal causes). Distal causes, however, could only be speculated (e.g., effects of site history, size, and location).

The alternative of adaptive restoration leads to clearer cause-effect relationships, while simultaneously accomplishing goals, such as revegetation with native plants. Planting seedlings at Tijuana Estuary at different levels of species-richness not only demonstrated that six-species assemblages accelerated ecosystem development over singlespecies, but the effort also indicated that most of the halophytes need to be planted to prevent dominance by pickleweed.

Where practicable, I suggest that restoration sites be designed as experiments that test alternative restoration methods and that large projects be planned as sequential modules so that knowledge gained from early experiments can inform later efforts. Over time, knowledge will grow so that restoration actions can be prescribed for a broad range of restoration contexts.

\section{Acknowledgements}

Funding for salt marsh experimentation was provided by the National Science Foundation (DEB 96-19875 and DEB 02-12005) and Earth Island Institute. Research on reed canary grass was funded by EPA Agreement No. R-82801001-1 (with K. Potter and R. Lathrop), and experimentation at Greene Prairie was supported by an anonymous donor. I thank my colleagues, John Callaway, Gary Sullivan, Sharook Madon, Quentin Carpenter, Suzanne Kercher, Roberto Lindig-Cisneros, Hem Nalini Morzaria-Luna, and Julia Wilcox for previous and ongoing collaborations. Comments of William Conner and an anonymous reviewer improved the text.

\section{References}

Ashworth S. 1997. Comparison between restored and reference sedge meadow wetlands in south-central Wisconsin. Wetlands 17: 518-527.

Covin J.D. and Zedler J.B. 1988. Nitrogen effects on Spartina folios a and Salicornia virginic a in the salt marsh at Tijuana Estuary, California. Wetlands 8: 51-65.

Dahl T. 1990. Wetlands losses in the United States 1780s to 1980s. U.S. Department of the Interior, Fish and Wildlife Service, Washington, DC, USA, 13 pp.

Desmond J., Zedler J.B. and Williams G.D. 2000. Fish use of tidal creek habitats in two southern California salt marshes. Ecological Engineering 14: 233-252.

Egler F. 1954. Vegetation science concepts. I. Initial floristic composition a factor in old-field vegetation development. Vegetation 14: 412-417.

Galatowitsch S.M. and van der Valk A.G. 1996. The vegetation of restored and natural prairie wetlands. Ecological Applications 6: 102-112. 
Hey D.L. and Philippi N.S. 1999. A Case for Wetland Restoration. John Wiley and Sons, Inc., NY, USA, 215 pp.

Keer G. and Zedler J.B. 2002. Salt marsh canopy architecture differs with the number and composition of species. Ecological Applications 12: 456-473.

Kercher S.M. and Zedler J.B. Differential flood tolerance of 17 herbaceous taxa. Aquatic Botany (In review).

Kercher S.M. and Zedler J.B. 2004. Multiple disturbances accelerate invasion of reed canary grass (Phalaris arundinacea L.) in a mesocosm study. Oecologia 138: 455-464.

Kitchen A. 2002. An assessment of landowner participation and habitat accomplishments: Monitoring Report for Wisconsin (1987-1999). Partners for Fish and Wildlife Program, US Fish and Wildlife Service, Madison, WI, USA, 22 pp.

Lindig-Cisneros R. and Zedler J.B. 2002. Halophyte recruitment in a salt marsh restoration site. Estuaries 25: 1175-1184.

Madon S.P., Williams G.D., West J.M. and Zedler J.B. 2001 The importance of marsh access to growth of the California killifish, Fundulus parvipinnis, evaluated through bioenergetics modeling. Ecological Modelling 136: 149-165.

Maurer D.A. and Zedler J.B. 2002. Differential invasion of a wetland grass explained by tests of nutrients and light availability on establishment and vegetative growth. Oecologia 131: 279-288.

Maurer D.A., Lindig-Cisneros R., Werner K.J., Kercher S., Miller R. and Zedler J.B. The replacement of wetland vegetation by Phalaris arundinacea (reed canary grass). Ecological Restoration (in press)
Miller R.C. and Zedler J.B. 2003. Responses of native and invasive wetland plants to hydroperiod and water depth. Plant Ecology 167: 57-69.

Werner K.J. and Zedler J.B. 2002. How sedge meadow soils, microtopography, and vegetation respond to sedimentation. Wetlands 22: 451-466.

West J.M. and Zedler J.B. 2000. Marsh-creek connectivity: fish use of a tidal salt marsh in southern California. Estuaries 23: 699-710.

Zedler J.B. and Callaway J.C. 2003. Adaptive restoration: a strategic approach for integrating research into restoration projects. In: Rapport D.J., Lasley W.L., Rolston D.E., Nielsen N.O., Qualset C.O. and Damania A.B. (eds), Managing for Healthy Ecosystems, Lewis Publishers, Boca Raton, FL, USA, pp. 167-174

Zedler J.B., Callaway J.C. and Sullivan G. 2001. Declining biodiversity: why species matter and how their functions might be restored. BioScience 51: 1005-1017.

Zedler J.B., Morzaria-Luna H.N. and Ward K. 2003. The challenge of restoring vegetation on tidal, hypersaline substrates. Plant and Soil 253: 259-273.

Zedler J.B., Nordby C.S. and Kus B. 1992. The ecology of Tijuana Estuary: A National Estuarine Research Reserve. NOAA Office of Coastal Resource Management, Sanctuaries and Reserves Division, Washington, DC, USA.

Zedler J.B., Callaway J.C., Desmond J., Vivian-Smith G., Williams G., Sullivan G., Brewster A. and Bradshaw B. 1999. Californian salt marsh vegetation: an improved model of spatial pattern. Ecosystems 2: 19-35. 